\title{
Temporal feed restriction and overstocking increase competition for feed by dairy cattle
}

\author{
L. K. M. Collings, D. M. Weary, N. Chapinal, and M. A. G. von Keyserlingk ${ }^{1}$ \\ Animal Welfare Program, Faculty of Land and Food Systems, University of British Columbia, 2357 Main Mall, Vancouver, BC, V6T 1Z4, Canada
}

\begin{abstract}
Dairy cows are often overstocked. Some managers are now using "slick bunk" (i.e., feeding for $0 \%$ orts) management to save on feed costs, but this reduces the time that cows have access to feed. Both practices may increase competition and affect feeding behavior in dairy cows. The aim was to determine the effects of temporal and spatial restrictions on the feeding and competitive behavior of group-housed cows. Treatments were 2 levels of stocking (2:1 versus 1:1 cows:feed bin) and 2 levels of feed access time (14 versus $24 \mathrm{~h} / \mathrm{d}$ access). Eight groups (each of 6 cows) were tested on each of the 4 treatment combinations for $1 \mathrm{wk}$, with treatment order assigned using a replicated $4 \times 4$ Latin square design. Dry matter intake (DMI), feeding time, and feeding rate were measured for the last $4 \mathrm{~d}$ of each week, and data were summarized daily and for the 2-h period immediately after the morning feeding. Displacements were recorded for $2 \mathrm{~h}$ after the delivery of morning feed (peak feeding period) and $2 \mathrm{~h}$ following the afternoon milking. The DMI did not decline when temporal access was restricted (27.0 vs. $25.7 \pm 0.5 \mathrm{~kg} / \mathrm{d}$ ), and was not affected by overstocking $(26.4 \pm 1.9$, mean $\pm \mathrm{SD})$. Cows with restricted temporal access spent less time feeding (190.9 vs. $207.9 \pm 6.1 \mathrm{~min})$. Overstocked cows that were temporally restricted had greater feeding rates during the day (156 vs. $137 \pm 4 \mathrm{~g} / \mathrm{min}$ ) and especially during the peak feeding period (175 vs. $146 \pm 4$ $\mathrm{g} / \mathrm{min}$ ) compared with cows that were not restricted. In the peak feeding period, overstocked cows had reduced DMI (3.0 vs. $3.4 \pm 0.1 \mathrm{~kg} / \mathrm{h})$ and feeding times $(20.8$ vs. $25.8 \pm 1.0 \mathrm{~min} / \mathrm{h}$ ) and increased feeding rates (161 vs. $138 \pm 4 \mathrm{~g} / \mathrm{min})$. Cows with restricted temporal access had greater DMI (3.9 vs. $2.6 \pm 0.2 \mathrm{~kg} / \mathrm{h}$ ) and time spent feeding (27.3 vs. $19.2 \pm 1.3 \mathrm{~min} / \mathrm{h})$ during the peak feeding period compared with cows that had continuous access to feed. Restricting temporal access in conjunction with overstocking resulted in the greatest increase in daily displacements (15.0 vs. $3.8 \pm$
\end{abstract}

Received March 16, 2011.

Accepted June 23, 2011.

${ }^{1}$ Corresponding author: nina@mail.ubc.ca
1.4 displacements/d); the majority of these occurred during the peak feeding period. Adequate space and time to access feed is essential to minimize feed bunk competition in indoor group housing systems.

Key words: feeding management, stocking density, slick bunk feeding, welfare

\section{INTRODUCTION}

Feeding behavior in freestall-housed dairy cows is affected by feed bunk design (DeVries and von Keyserlingk, 2006; Huzzey et al., 2006) and feeding management, including feed bunk stocking density (Huzzey et al., 2006; Proudfoot et al., 2009) and fresh feed availability (DeVries et al., 2005). Feeding behavior is highly synchronized (Hafez and Boissou, 1975) and peaks immediately following the delivery of fresh feed and after milking (DeVries and von Keyserlingk, 2005). High-producing cows spend 3 to 6 h/d feeding, consuming approximately $23 \mathrm{~kg}$ of DM/d in 9 to 14 meals/d (Dado and Allen, 1994; Grant and Albright, 2000; Munksgaard et al., 2005).

The effects on feeding behavior of overstocking at the feed bunk, through either a reduction in space or an increase in the number of cows, have received considerable attention over the last decade. At increased stocking densities, cows increase direct competitive behavior through increased displacements at the feed bunk (Proudfoot et al., 2009) and compete indirectly by increasing their feeding rates (Olofsson, 1999). Subordinate cows are most affected, showing the greatest increases in feeding rate and reductions in DMI (Olofsson, 1999; Grant and Albright, 2001; Proudfoot et al., 2009). Interestingly, the effects of increased stocking density at the feed bunk on DMI, feeding time, and feeding rate are less for primiparous cows than for multiparous cows (Proudfoot et al., 2009), perhaps because primiparous cows typically consume less than multiparous cows.

Current industry practice provides cows with at least $0.6 \mathrm{~m} /$ cow of bunk space (NFACC, 2009) and 5\% excess feed (in relation to estimated requirements) to ensure access to feed $24 \mathrm{~h} / \mathrm{d}$ (Albright, 1993; Grant and Albright, 2001; NFACC, 2009). Some authors suggested 
that feed efficiency can be improved by reducing the amount of feed provided (Hicks et al., 1990; Hoffman et al., 2007), and a recent survey showed that a growing number of dairy producers are aiming for $0 \%$ orts, or a "slick bunk" (Silva-del-Río et al., 2010). In effect, slick bunk management results in some periods of the day when cows have little or no access to suitable feed, imposing a temporal restriction on feed availability.

Little is known about the effects of temporal restrictions in feed access. Munksgaard et al. (2005) studied the effects of reducing feed access to only $12 \mathrm{~h} / \mathrm{d}$ on the lying and feeding behavior of individually housed cows. Cows restricted from feed had lower feeding times and higher feeding rates and only slightly lower DMI. In a tie-stall environment, Erdman et al. (1989) tested the effects of providing feed for $8,12,16$, or $20 \mathrm{~h} / \mathrm{d}$, and found lower DMI but no change in feeding time with reduced feed access time. Chapinal et al. (2010a,b) examined the effects of overnight access to pasture, which included denying access to TMR during the night, and found no effect on milk production, TMR intake, or feeding time. However, cows that were denied access to TMR overnight compensated by spending more time feeding in the first $3 \mathrm{~h}$ after regaining access to TMR and displacing other cows from the feed bunk during this period (Chapinal et al., 2010b).

These effects of temporal restriction are similar to the effect of increased stocking density, perhaps because both factors can reduce cow access to feed. It seems likely that the effects of temporal restrictions may accentuate any effects of feed bunk overstocking on the feeding and social behavior of dairy cows. The aim was to determine the effects of temporal and spatial restriction separately and together on the feeding and social behavior of group-housed lactating cows.

\section{MATERIALS AND METHODS}

\section{Animals, Housing, and Diet}

Forty-eight multiparous lactating Holstein dairy cows were enrolled in this experiment. All animals were housed at the University of British Columbia Dairy Education and Research Centre (Agassiz, BC, Canada) and were cared for according to the guidelines of the Canadian Council on Animal Care (2009) and the National Farm Animal Care Council (NFACC, 2009). Cows on all treatments had ad libitum access to water, and were milked twice daily at approximately 0600 and $1700 \mathrm{~h}$. Cows were fed a TMR balanced according to the NRC (2001) recommendations. The TMR was fed at approximately 0615 and $0930 \mathrm{~h}$. Samples of TMR were collected twice weekly and frozen for storage at $-18^{\circ} \mathrm{C}$. Thawed samples were oven-dried at $60^{\circ} \mathrm{C}$ for
$48 \mathrm{~h}$ to determine DM. To calculate nutrient composition, samples were sent for analysis to Cumberland Valley Analytical Services Inc. (Maugansville, MD). The TMR consisted of $27.2 \%$ corn silage, $16.7 \%$ grass silage, $8.5 \%$ alfalfa, and $47.7 \%$ mineral and concentrate mix on a DM basis (DM: $56 \pm 2.5 \%$, CP: $16.8 \pm 0.5 \%$ DM, ADF: $21.8 \pm 0.2 \%$ DM, NDF: $35.9 \pm 0.8 \%$ DM, and $\left.\mathrm{NE}_{\mathrm{L}}: 1.64 \pm 0.01 \mathrm{Mcal} / \mathrm{kg}\right)$.

\section{Experimental Treatments and Design}

Each of the 4 experimental pens contained 6 electronic feed bins and 1 electronic water dispenser (Insentec, Marknesse, the Netherlands); cows had free access to all feed bins within a pen. Each pen had rubber flooring and contained 2 rows of 6 lying stalls each fitted with mattresses (Pasture Mat, Promat Inc., Woodstock, Ontario, Canada) and bedded with approximately $5 \mathrm{~cm}$ of washed river-sand. Stalls were raked twice daily while cows were away from the pen during milking, and fresh sand was added once weekly. Lying stalls were blocked according to treatment to maintain a cow to stall ratio of $1: 1$.

Cows were randomly assigned to groups of 6 , balanced by parity $(3.1 \pm 1.2$, mean $\pm \mathrm{SD}$, range from 2 to 6 lactations), projected 305-d milk production (12,603.3 $\pm 1,656.5 \mathrm{~kg})$, and DIM $(204.2 \pm 40.7 \mathrm{~d})$. Each group was exposed to each of the 4 treatments for $1 \mathrm{wk}$, with treatment order assigned using a randomized $4 \times 4$ Latin square. Two replications involving different focal cows were completed to give a total of 8 groups.

The 4 treatments were as follows: (1) 100\%-24h: $100 \%$ feed bunk stocking density, 24-h access to feed, (2) 100\%-14h: $100 \%$ feed bunk stocking density, $14-\mathrm{h}$ access to feed (0600 to 2000 h), (3) 200\%-24h: $200 \%$ feed bunk stocking density, 24-h access to feed, and (4) 200\%-14h: $200 \%$ feed bunk stocking density, 14-h access to feed (0600 to $2000 \mathrm{~h}$ ).

To create the densities of cows at the feed barrier (100 or 200\%), a group of 6 multiparous nonexperimental (filler) cows were added to or removed from groups of 6 focal cows. On the $100 \%$ treatments, 6 cows fed from 6 bins (1:1 cow:bin); on the $200 \%$ treatments, 12 cows fed from 6 bins (2:1). To create the 2 temporal feed access treatments, the feeding system was programmed to allow cows access to the feed bins for 14 or $24 \mathrm{~h} / \mathrm{d}$.

The first $3 \mathrm{~d}$ of each treatment week were considered as an acclimation period in an attempt to minimize any carryover effects from the previous treatment. Data were collected on the last $4 \mathrm{~d}$ of the treatment week.

Feeding and Social Behavior. The DMI was continuously monitored using the Insentec feeding system (Insentec) previously validated by Chapinal et al. (2007). In summary, the Insentec system recorded the 
duration of each visit to the feed bins as well as the amount of TMR consumed by the cow. For each visit to the feed bins, feeding rate was calculated using the amount consumed and time spent at the feeder. Social behavior was recorded using a video camera (WVCW504SP Dome and WV-BP330, Panasonic, Osaka, Japan) placed $6 \mathrm{~m}$ over the feed bunk, connected to a digital recording system (GeoVision, Inc., Irvine, CA). Each cow was marked (L'Oreal Paris Perfect Blondissima, L'Oreal, New York, NY; and Clairol Nice'n Easy 124 Natural Blue Black, Procter and Gamble, Cincinnati, $\mathrm{OH}$ ) with a unique alphanumeric symbol for identification purposes. Preliminary analyses based on data from $10 \mathrm{~d}$ indicated that continuous recording of displacements from the feed bins for $2 \mathrm{~h}$ following the first feeding and $2 \mathrm{~h}$ following the afternoon milking explained the majority of the variation associated with displacements recorded over a full $24 \mathrm{~h}\left(\mathrm{R}^{2}=0.96\right.$; $P<0.001)$. Displacements were recorded during the last $4 \mathrm{~d}$ of each treatment week. A displacement was defined as a butt or a push from a focal cow "actor" that resulted in the complete withdrawal of the head of the "reactor" (either a focal or filler cow) from the feed bin. Intra- and interobserver reliability for number of displacements recorded were $\mathrm{R}^{2}=1.0$ and $\mathrm{R}^{2}=0.98$, respectively $(P<0.002)$.

Lying Behavior. Standing and lying behaviors were recorded using an activity data logger (Hobo Pendant G, Onset Computer Corp., Cape Cod, MA) fitted to 1 hind leg of each cow. Each minute, the data logger recorded the position of the leg as either standing or lying (Ledgerwood et al., 2010). These data were used to determine daily lying time as well as the frequency and duration of lying bouts. Daily nonfeeding standing time was calculated by subtracting the time spent feeding from the time spent standing.

Milk Production. On each experimental day, milk production was recorded for each cow at the morning and afternoon milkings. These 2 values were summed to provide 1 daily value per cow $(\mathrm{kg} / \mathrm{d})$.

\section{Statistical Analysis}

All cows were gait scored before the start of the experiment using the locomotion scoring system developed by Flower and Weary (2006). One cow was diagnosed as lame and removed from the experiment. To maintain stocking density, a filler cow took the place of the lame cow when she was removed from the pen. The remaining 47 cows were used in the analysis.

Statistical analyses were conducted using SAS version 9.2 (SAS Institute, 2009). Each group of focal cows was considered the experimental unit ( $\mathrm{n}=8$ groups). Feeding behavior data from the Insentec system was screened for outliers using PROC UNIVARIATE (SAS Institute, 2009). Based on feeding rate, of the 33,095 feeding events, $1.6 \%$ were identified as extreme outliers (more than 3 times the interquartile range below the first quartile or above the third quartile) and were removed. Using PROC UNIVARIATE, no extreme outliers were detected in the social or lying behavior measures. For each group, data were averaged across the $4 \mathrm{~d}$ and the 6 focal cows of each group to provide 1 value per group per treatment, expressed on a per day and per cow basis (average DMI/d per cow) or a per hour per cow basis (average DMI/h per cow).

The MIXED procedure in SAS was used to test the effects of overstocking, feed restriction, and the interaction between these effects for feeding behavior variables (DMI, $\mathrm{kg} / \mathrm{d}, \mathrm{kg} / \mathrm{h}$; feeding time, $\mathrm{min} / \mathrm{d}, \mathrm{min} / \mathrm{h}$; feeding rate, $\mathrm{g} / \mathrm{min}$; frequency of visits, no./d, no./h), social behavior (displacements initiated/d; displacements initiated/h), lying behavior (lying time, $\mathrm{h} / \mathrm{d}$; frequency of lying bouts, no./d; nonfeeding standing time, h/d), and milk production $(\mathrm{kg} / \mathrm{d})$. Group was considered a random effect in the model and variance components covariance structure was used. Specific contrast statements were used when an interaction was detected between the main effects. Contrast statements were used to test differences between densities for each feed access time and differences between different feed access times for each stocking density. The LSMEANS function in the MIXED procedure was used to determine least squares means and standard errors. Tendencies are reported at $P<0.1$ and significant results at $P<0.05$ for all tests.

\section{RESULTS}

\section{Feeding Behavior}

Over a 24-h period, groups of cows that were overstocked at the feeder had similar daily DMI and number of visits to the feeder compared with nonoverstocked cows, but the overstocked cows tended to spend less time feeding (Table 1). Groups that were unable to access feed at night tended to have lower DMI compared with unrestricted cows, and spent less time eating (190.9 vs. $207.9 \pm 6.1 \mathrm{~min} / \mathrm{d})$ with fewer visits to the feed bins ( 41.1 vs. $45.6 \pm 2.5$ ). No other differences were observed among treatments in these response variables.

An interaction $(P<0.0001)$ was found between overstocking and temporal restriction on feeding rate. Feeding rate was highest when overstocking and temporal restriction were combined. Indeed, rates during the combined treatment were higher than when cows were overstocked without temporal restriction (156 vs. $137 \pm$ $4 \mathrm{~g} / \mathrm{min} ; P<0.0001)$ and higher than when cows were temporally restricted without overstocking (156 vs. 133 
Table 1. Least squares means and SEM responses for 8 groups of cows, each tested under 4 treatments and the $P$-values for main effects (stocking density and feed access time) and interaction ${ }^{1}$

\begin{tabular}{|c|c|c|c|c|c|c|c|c|}
\hline \multirow[b]{2}{*}{ Variable } & \multicolumn{4}{|c|}{ Treatment $^{2}$} & \multirow[b]{2}{*}{ SEM } & \multicolumn{3}{|c|}{$P$-value } \\
\hline & $100 \%-24 \mathrm{~h}$ & $100 \%-14 \mathrm{~h}$ & $200 \%-24 \mathrm{~h}$ & $200 \%-14 \mathrm{~h}$ & & Density & Access & $\begin{array}{c}\text { Density } \times \\
\text { access }\end{array}$ \\
\hline \multicolumn{9}{|l|}{ Daily values } \\
\hline DMI (kg/d) & 27.2 & 25.6 & 26.8 & 25.9 & 0.6 & 0.92 & 0.06 & 0.57 \\
\hline Feeding time $(\mathrm{min} / \mathrm{d})$ & 211.0 & 199.0 & 204.8 & 182.9 & 7.2 & 0.05 & 0.005 & 0.36 \\
\hline Feeding rate (g/min) & 135 & 133 & 137 & 156 & 4 & $<0.0001$ & $<0.0001$ & $<0.0001$ \\
\hline Frequency of lying bouts (no./d) & 8.4 & 8.5 & 8.4 & 8.0 & 0.5 & 0.26 & 0.60 & 0.36 \\
\hline Nonfeeding standing time $(\mathrm{h} / \mathrm{d})$ & 10.2 & 9.8 & 9.8 & 10.7 & 0.4 & 0.57 & 0.60 & 0.10 \\
\hline Displacements initiated (no./d) & 3.8 & 5.7 & 7.4 & 15.0 & 1.4 & $<0.0001$ & 0.0002 & 0.01 \\
\hline \multicolumn{9}{|l|}{$2 \mathrm{~h}$ after morning feed delivery } \\
\hline DMI (kg/h) & 2.7 & 4.1 & 2.4 & 3.7 & 0.2 & 0.02 & $<0.0001$ & 0.52 \\
\hline Feeding time $(\mathrm{min} / \mathrm{h})$ & 20.6 & 31.0 & 17.9 & 23.6 & 1.3 & 0.0001 & $<0.0001$ & 0.04 \\
\hline Feeding rate $(\mathrm{g} / \mathrm{min})$ & 139 & 137 & 146 & 175 & 4 & $<0.0001$ & $<0.0001$ & $<0.0001$ \\
\hline
\end{tabular}

${ }^{1}$ Means are shown separately for observations throughout the day and for the $2 \mathrm{~h}$ after fresh feed was delivered in the morning.

${ }^{2}$ Treatments: $100 \%-24 \mathrm{~h}=100 \%$ feed bunk stocking density, 24 - $\mathrm{h}$ access to feed; $100 \%-14 \mathrm{~h}=100 \%$ feed bunk stocking density, 14 -h access to feed ( 0600 to $2000 \mathrm{~h}$ ); $200 \%-24 \mathrm{~h}=200 \%$ feed bunk stocking density, 24 -h access to feed; and $200 \%-14 \mathrm{~h}=200 \%$ feed bunk stocking density, 14 -h access to feed (0600 to $2000 \mathrm{~h})$.

$\pm 4 \mathrm{~g} / \mathrm{min} ; P<0.0001)$. No other differences in feeding rate were observed among treatments.

The effects of competitive feeding and temporal restriction were most noticeable during the $2 \mathrm{~h}$ after morning feeding. The DMI and visits to the feeder were greater during this period for cows that were temporally restricted. Overstocked cows had reduced DMI $(6.1$ vs. $6.9 \pm 0.3 \mathrm{~kg} / \mathrm{d})$, but had greater feeding rates (160.9 vs. $137.8 \pm 3.9 \mathrm{~g} / \mathrm{min})$ and tended to visit the feeder more often. An interaction $(P=0.04)$ was found between overstocking and temporal restriction on feeding time during this 2 -h feeding period. Cows that were both overstocked and feed restricted spent less time feeding than those that were feed restricted but not overstocked $(P<0.0001)$. When cows were temporally restricted they spent more time feeding than cows that were not restricted when stocked at $100 \%(P<0.0001)$ and $200 \%(P=0.001)$. Overstocking $(P=0.09)$ had no effect when feed access was not temporally restricted.

A pattern of DMI affected by both stocking density and temporal restriction is in Figure 1. The largest peak in feeding activity was $2 \mathrm{~h}$ after the delivery of morning feed, with a smaller peak after the second morning feeding and in the afternoon following milking. Cows restricted from feeding overnight showed the greatest peak in DMI during the morning period. Cows that had access to feed $24 / \mathrm{d}$ consumed between 0 and $0.5 \mathrm{~kg}$ of $\mathrm{DM} / \mathrm{h}$ overnight.

\section{Social Behavior}

An interaction was found between treatments for daily displacements and displacements during the $2 \mathrm{~h}$ after morning feeding ( $P<0.01$ in both cases). Combining overstocking and temporal feed restriction resulted in a greater number of displacements initiated per cow compared with overstocking alone (24-h period, 15.0 vs. $7.4 \pm 1.4, P<0.0001 ; 2$-h period, 5.6 vs. $2.4 \pm 0.6$, $P<0.0001$ ). For both periods, overstocking resulted in a greater number of displacements with (24-h period, $P<0.0001 ; 2$-h period, $P<0.0001)$ and without $(24-$ h period, $P=0.02 ; 2$-h period, $P=0.04$ ) temporal restriction in feed access. Temporal restriction had no effect when cows were stocked at $100 \%$ for either daily displacements or displacements during the $2 \mathrm{~h}$ after morning feeding.

\section{Lying Behavior and Milk Production}

Feed restriction and stocking density at the feed bunk had no effect on daily lying time, frequency of lying bouts, or nonfeeding standing time. Treatment had no effect on milk production. Cows produced $36.5 \pm 2.6$ $\mathrm{kg} / \mathrm{d}$ (mean $\pm \mathrm{SD}$ ) for the duration of the experiment.

\section{DISCUSSION}

This study was the first to examine the effects of temporal restriction in access to feed on the behavior of a stable group of lactating dairy cows and the first to test how this restriction interacts with the effect of overstocking. The results show that both management practices negatively affect feeding and social behavior.

Overstocked groups consumed $11 \%$ less feed than groups that were not overstocked during the $2 \mathrm{~h}$ fol- 


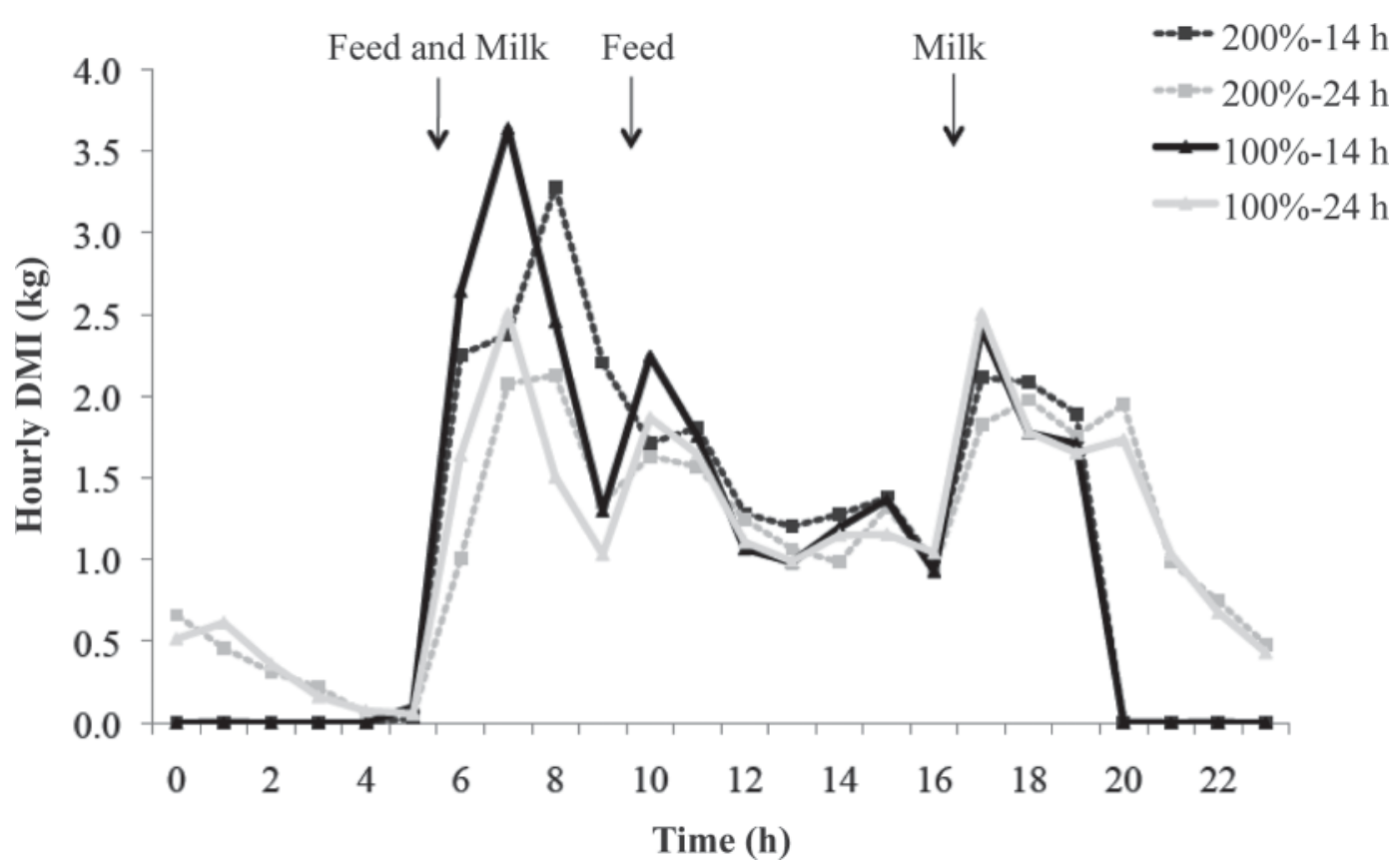

Figure 1. The temporal pattern of hourly DMI (kg) averaged for 8 groups of cows for each stocking density (100 and $200 \%)$ and feed access treatment $(14 \mathrm{~h}$ and $24 \mathrm{~h} / \mathrm{d})$. For the restricted feed access treatment, feed bins were programmed to prevent access between 2000 and $0600 \mathrm{~h}$.

lowing fresh feed delivery when cows are highly motivated to feed (DeVries and von Keyserlingk, 2005). The overstocked cows compensated for the reduction in feed intake by increasing DMI in the hours following, resulting in similar DMI over a 24-h period. Hosseinkhani et al. (2008) reported reduced DMI for overstocked cows during peak feeding periods and greater DMI in the hours following.

Previous studies on close-up cows (Hosseinkhani et al., 2008) and fresh cows (Proudfoot et al., 2009) reported an increase in daily feeding rate when overstocked. The current study supported increased feed consumption rates for overstocked lactating cows during the 2-h period after morning feeding.

During the $2 \mathrm{~h}$ after they were first allowed access to feed in the morning, feed-restricted cows consumed $50 \%$ more DM (1.3 kg/h more) than nonrestricted cows. Temporally restricted cows that were overstocked ate at a faster rate. Previous work showed that feeding rate increased after the delivery of fresh feed (DeVries and von Keyserlingk, 2005) and was greater in animals that were more motivated to feed (Nielsen, 1999). Nonrestricted cows consumed less DM during the peak feeding period, but with the opportunity to eat overnight, they were able to spread their DMI more evenly throughout the 24-h period and consumed the same amount of $\mathrm{DM} / \mathrm{d}$ as the restricted cows.

A potential concern with restricting feed is the spike in DMI when feed is first provided (Stone, 2004). In the current study, the $100 \%$ restricted group consumed more than $8 \mathrm{~kg}$ of DM/cow in the $2 \mathrm{~h}$ after the morning feeding. Measures of rumen function were not included in the current study, but we encourage future research to assess the effects of temporal restrictions in feed access on rumen $\mathrm{pH}$ and subacute ruminal acidosis, because these responses are associated with periods of slug feeding (Owens et al., 1998; Krause and Oetzel, 2006).

Supporting previous literature, overstocking and restricting feed access time caused increases in the number of displacements at the feed bunk, especially during the peak morning period (Huzzey et al., 2006; Proudfoot et al., 2009; Chapinal et al., 2010b). Feedrestricted cows were highly motivated to eat, as they needed to consume their daily TMR in a shorter period. When cows were not overstocked, all animals were able to eat simultaneously, perhaps explaining why the temporal restriction had less effect on displacements at the $100 \%$ stocking level. When temporal feed restriction was combined with overstocking, a doubling in the number of displacements occurred relative to the other treatments. These results indicate that slick bunk management may be especially problematic when combined with overstocking at the feed bunk.

In the current study, daily lying times and daily nonfeeding standing time did not differ, supporting Chapinal et al. (2010b), but others reported that lying time was reduced with overstocking, with this difference 
driven by more time standing in the feeding area waiting to access feed (Huzzey et al., 2006; Proudfoot et al., 2009). The variability in this response across studies may be due in part to the high among-cow variability in standing and lying behaviors (Ito et al., 2009).

Cows are crepuscular feeders, consuming most of their daily intake between dawn and dusk (Hafez and Boissou, 1975). Results from the present study and from DeVries and von Keyserlingk (2006) suggest that cows adjust their feeding pattern based on management factors such as competition at the feed area due to overstocking or feed restriction. Although overstocked cows are able to compensate for reduced DMI during the peak feeding period by eating in the hours following, competition may be detrimental to individual cows. DeVries et al. (2005) and Huzzey et al. (2006) stated that the effects of competition at the feed bunk were greatest for subordinate cows.

This study focused on the short-term effects of reduced feeding space and reduced feed access time. In a commercial setting, cows may be subjected to these environmental constraints for long periods, which may lead to more detrimental effects, or may provide cows the opportunity to compensate, thus reducing the effects described here. The period of feed restriction in this study (10 h restricted/d) was most likely longer than cows would typically experience when fed to a slick bunk. Yet, on-farm documentation of the amount of time cows do not have access to feed when fed for a slick bunk has not been reported and is likely variable across farms. Further research should explore the effects of various feed restriction times on feeding and competitive behavior.

\section{CONCLUSIONS}

Overstocking at the feed bunk and overnight feed restriction increased competition at the feed bunk and changed feeding behavior, especially during peak feeding periods. Combining overstocking with a period of feed restriction may be problematic in terms of competitive and feeding behavior for lactating dairy cows.

\section{ACKNOWLEDGMENTS}

We are grateful to the students and staff of the University of British Columbia Animal Welfare Program and the Dairy Education and Research Centre, including Mike Duncan, Brad Duncan, Bill Kramer, Dan Peters, Ted Toenders, Barry Thompson, and Nelson Dinn. We thank Jacqueline Heil and Lori Vickers for their support carrying out the experiment, and Eliza Christie for her help in scoring videos. Lindsay Collings was funded, in part, by the Viterra Graduate Fellowship.
The Animal Welfare Program is funded by Canada's Natural Sciences and Engineering Research Council (Ottawa, ON, Canada) Industrial Research Chair Program with industry contributions from the Dairy Farmers of Canada (Ottawa, ON, Canada), Westgen Endowment Fund (Milner, BC, Canada), Pfizer Animal Health (Kirkland, QC, Canada), BC Cattle Industry Development Fund (Kamloops, BC, Canada), the BC Milk Producers (Burnaby, BC, Canada), BC Dairy Foundation (Burnaby, BC, Canada), BC Dairy Education and Research Association (Abbotsford, BC, Canada), and Alberta Milk (Edmonton, AB, Canada).

\section{REFERENCES}

Albright, J. L. 1993. Feeding behavior of dairy cattle. J. Dairy Sci. $76: 485-498$.

Canadian Council on Animal Care. 2009. Guidelines on the Care and Use of Farm Animals in Research, Teaching and Testing. CCAC, Ottawa, Ontario, Canada.

Chapinal, N., C. Goldhawk, A. M. de Passillé, M. A. G. von Keyserlingk, D. M. Weary, and J. Rushen. 2010a. Overnight access to pasture does not reduce milk production or feed intake in dairy cattle. Livest. Sci. 129:104-110.

Chapinal, N., D. M. Veira, D. M. Weary, and M. A. G. von Keyserlingk. 2007. Technical note: Validation of a system for monitoring individual feeding and drinking behavior and intake in grouphoused dairy cattle. J. Dairy Sci. 90:5732-5736.

Chapinal, N., D. M. Weary, J. Rushen, A. M. de Passillé, and M. A. G. von Keyserlingk. 2010b. Short communication: Effects of temporal restriction in availability of the total mixed ration on feeding and competitive behavior in lactating dairy cows. Livest. Sci. 137:282-286 doi:10.1016/j.livsci.2010.11.006.

Dado, R. G., and M. S. Allen. 1994. Variation in and relationships among feeding, chewing, and drinking variables for lactating dairy cows. J. Dairy Sci. 77:132-144.

DeVries, T. J., and M. A. G. von Keyserlingk. 2005. Time of feed delivery affects the feeding and lying patterns of dairy cows. J. Dairy Sci. 88:625-631.

DeVries, T. J., and M. A. G. von Keyserlingk. 2006. Feed stalls affect the social and feeding behavior of lactating dairy cows. J. Dairy Sci. 89:3522-3531.

DeVries, T. J., M. A. G. von Keyserlingk, and K. A. Beauchemin. 2005. Frequency of feed delivery affects the behavior of lactating dairy cows. J. Dairy Sci. 88:3553-3562.

Erdman, R. A., T. W. Moreland, and W. R. Stricklin. 1989. Effect of time of feed access on intake and production in lactating dairy cows. J. Dairy Sci. 72:1210-1216.

Flower, F. C., and D. M. Weary. 2006. Effect of hoof pathologies on subjective assessments of dairy cow gait. J. Dairy Sci. 89:139-146.

Grant, R. J., and J. L. Albright. 2000. Feeding Behaviour. Page 365382 in Farm Animal Metabolism and Nutrition. J. P. F. D'Mello, ed. CABI Publishing, Wallingford, UK.

Grant, R. J., and J. L. Albright. 2001. Effect of animal grouping on feeding behavior and intake of dairy cattle. J. Dairy Sci. 84(ESuppl.):E156-E163.

Hafez, E. S. E., and M. F. Boissou. 1975. The behaviour of cattle. Pages 203-245 in The Behaviour of Domestic Animals. 3rd ed. E. S. E. Hafez, ed. Bailliere Tindall, London, UK.

Hicks, R. B., F. N. Owens, D. R. Gill, J. J. Martin, and C. A. Strasia. 1990. Effects of controlled feed intake on performance and carcass characteristics of feedlot steers and heifers. J. Anim. Sci. 68:233-244.

Hoffman, P. C., C. R. Simson, and M. Wattiaux. 2007. Limit feeding of gravid Holstein heifers: Effect on growth, manure nutrient excretion, and subsequent early lactation performance. J. Dairy Sci. 90:946-954. 
Hosseinkhani, A., T. J. DeVries, K. L. Proudfoot, R. Valizadeh, D. M. Veira, and M. A. G. von Keyserlingk. 2008. The effects of feed bunk competition on the feed sorting behavior of close-up dry cows. J. Dairy Sci. 91:1115-1121.

Huzzey, J. M., T. J. DeVries, P. Valois, and M. A. G. von Keyserlingk. 2006. Stocking density and feed barrier design affect the feeding and social behavior of dairy cattle. J. Dairy Sci. 89:126-133.

Ito, K., D. M. Weary, and M. A. G. von Keyserlingk. 2009. Lying behavior: Assessing within- and between-herd variation in free-stallhoused dairy cows. J. Dairy Sci. 92:4412-4420.

Krause, K. M., and G. R. Oetzel. 2006. Understanding and preventing subacute ruminal acidosis in dairy herds: A review. Anim. Feed Sci. Technol. 126:215-236.

Ledgerwood, D. N., C. Winckler, and C. B. Tucker. 2010. Evaluation of data loggers, sampling intervals, and editing techniques for measuring the lying behavior of dairy cattle. J. Dairy Sci. 93:5129-5139.

Munksgaard, L., M. B. Jensen, L. J. Pedersen, S. W. Hansen, and L. Matthews. 2005. Quantifying behavioural priorities-Effects of time constraints on behaviour of dairy cows, Bos taurus. Appl. Anim. Behav. Sci. 92:3-14.

National Research Council. 2001. Nutrient Requirements of Dairy Cattle. 7th rev. ed. National Academy Press, Washington, DC.
NFACC. 2009. Code of practice for the care and handling of dairy cattle. Dairy Farmers of Canada and the National Farm Animal Care Council, Ottawa, Ontario, Canada.

Nielsen, B. L. 1999. On the interpretation of feeding behavior measures and the use of feeding rate as an indicator of social constraint. Appl. Anim. Behav. Sci. 63:79-91.

Olofsson, J. 1999. Competition for total mixed diets fed for ad libitum intake using one or four cows per feeding station. J. Dairy Sci 82:69-79.

Owens, F. N., D. S. Secrist, W. J. Hill, and D. R. Gill. 1998. Acidosis in cattle: A review. J. Anim. Sci. 76:275-286.

Proudfoot, K. L., D. M. Veira, D. M. Weary, and M. A. G. von Keyserlingk. 2009. Competition at the feed bunk changes the feeding, standing, and social behavior of transition dairy cows. J. Dairy Sci. 92:3116-3123.

SAS Institute. 2009. SAS User's Guide. Version 9.2. SAS Institute Inc., Cary, NC.

Silva-del-Río, N., J. M. Heguy, and A. Lago. 2010. Feed management practices on California dairies. J. Dairy Sci. 93(E-Suppl. 1):773 (Abstr.)

Stone, W. C. 2004. Nutritional approaches to minimize subacute ruminal acidosis and laminitis in dairy cattle. J. Dairy Sci. 87(ESuppl.):E13-E26. 